\title{
Characterization and outcomes of urethroplasty for hypospadias-associated urethral strictures in adults
}

\author{
Alvaro A. Saavedra MD; Keith F. Rourke, MD, FRCSC \\ Division of Urology, Department of Surgery, University of Alberta, Edmonton, AB, Canada
}

Cite as: Can Urol Assoc J 2019 April 26; Epub ahead of print. http://dx.doi.org/10.5489/cuaj.5863

Published online April 26, 2019

$* * *$

\begin{abstract}
Introduction: Urethral stricture is one of the most commonly encountered complications after hypospadias repair but remains poorly described. The aim of this study is to better characterize hypospadias-associated urethral strictures (HAUS) and treatment outcomes.

Methods: We conducted a retrospective analysis of 84 patients who underwent urethroplasty (UP) for HAUS from 2003-2017. Patients were characterized with regard to demographics, stricture length, location, concurrent pathology, previous surgery, type of urethroplasty, 90-day complications, and surgical success defined as the absence of stricture on cystoscopy. Univariate and survival multivariate analysis was performed.

Results: Overall success was $88.1 \%$ at a mean followup of 19 months, with a 90-day complication rate of $9.5 \%$, a $21.4 \%$ rate of urethrocutaneous fistula requiring a mean of 1.4 surgeries. Patients were categorized into one of four groups based on stricture length, location, and number of previous procedures: group 1 (66.7\%) - previous failed hypospadias repair (HR) with stricture involving the entire repair; group 2 (7.1\%) - "junctional stricture" at the junction of the "neourethra" and native urethra; group 3 (11.9\%) - isolated bulbar stricture outside the repaired urethra; group 4 (14.3\%) - urethral stricture in untreated hypospadias. Despite differing by technique $(\mathrm{p}<0.0001)$, stricture length $(\mathrm{p}=0.02)$, location $(\mathrm{p}<0.001)$, and number of previous repairs $(p<0.001)$, groups did not significantly differ by success $(p=0.82)$, complications $(\mathrm{p}=0.16)$, or urethrocutaneous fistula $(\mathrm{p}=0.19)$, whereas individual techniques did.

Conclusions: UP for HAUS is often successful but patients frequently require more than one operation and have a significant risk of associated complications. Despite a broad spectrum of presentation, patients can often be categorized into one of four groups, which can help direct decision-making and obtain similar outcomes regardless of baseline differences.
\end{abstract}




\section{Introduction}

Hypospadias is one of the most common congenital urologic conditions and may be increasing in both incidence and severity. ${ }^{1}$ Despite improvements in hypospadias surgical techniques there is still a significant and varied rate of complications. ${ }^{2}$ For example, in large population based studies approximately $9 \%$ of patients will require a secondary surgery during childhood even in the setting of distal hypospadias. ${ }^{3}$ While severity of hypospadias, low surgeon volume, preputial flaps, tubularized tissue and increased patient age are often cited as factors associated with complications such as stricture, the rate of complications may be underestimated due to relatively short-term follow-up in the majority of series. ${ }^{4}$ In fact, many complications including urethrocutaneous fistula are often detected only after the second year of follow-up or after the onset of puberty. ${ }^{5}$ With minimal prospective longitudinal data available, the true proportion of complications arising in adulthood remains unknown. Regardless of reason or incidence, adults presenting with hypospadias complications do so with a wide spectrum of symptoms, abnormalities, etiologies and expectations. ${ }^{6}$

As a cause of urethral stricture, HAUS is relatively common. ${ }^{7}$ Palminteri et al, published data from 1,439 patients who underwent urethroplasty for stricture and demonstrated that $12.2 \%$ were related to previous hypospadias repair (PHR). ${ }^{8}$ Specifically, HAUS represents $31.7 \%$ of all iatrogenic cases and $31.9 \%$ of all penile strictures. ${ }^{8}$ Other studies also suggest that the most common complication of hypospadias repair is urethral stricture, found in up to $72 \%$ of patients presenting with hypospadias complications. ${ }^{9}$ While it is likely that contemporary surgical techniques will bring better long-term outcomes, the increasing severity of hypospadias may temper a reduction in complications such as stricture. ${ }^{1}$

In spite of being one of the most frequent complications of hypospadias, HAUS still remains poorly described which has led to difficulties comparing outcomes and studies. ${ }^{10,11}$ In general, hypospadias complications can be broadly classified as to whether or not the patient had prior urethral surgery. ${ }^{6,12}$ However, this description omits a significant amount of complexity and may not differentiate between the majority of patients. Factors such as the severity of hypospadias, prior surgery, stricture length, location, fibrosis, glans appearance, and sexual function can result in an enormous variety of HAUS. ${ }^{6,10}$ Thereby, the aims of this study are to better characterize the clinical presentation and outcomes of HAUS, which in turn will help better classify the entity and facilitate a decision-making framework. Our hypothesis is that HAUS, despite being complex have classifiable patterns of clinical presentation and satisfying treatment outcomes.

\section{Methods}

From August 2003 to July 2017, 1, 202 urethroplasties were performed by a single reconstructive surgeon. After institutional health ethics approval was obtained, charts of all patients who underwent urethroplasty for HAUS in this period were retrospectively reviewed. Those with less than 6 months of follow-up were excluded. Information about age at presentation, comorbidities 
(individual and Charlson comorbidity index), lichen sclerosus, erectile function, chordee, previous endoscopic treatment, prior surgery, 90-day postoperative complications (with ClavienDindo grade), length of stay (LOS) and stricture recurrence were reviewed. ${ }^{13}$ All patients underwent cystoscopy and retrograde urethrogram preoperatively as well as cystoscopy at 6 and 18 months postoperatively.

Based on identifiable patterns, patients were classified into one of 4 categories based on previous surgery, stricture length, and location. Group 1: The long “pan-penile” stricture involving the majority of the penile urethra in the setting of previous (and often multiple) hypospadias surgeries, Group 2: The "junctional stricture" with a hypospadias repair deemed acceptable but having a stricture of variable length at the junction of previous hypospadias repair and native urethra, Group 3: Isolated bulbar urethral stricture after hypospadias repair outside of the previously repaired urethra, Group 4: Urethral stricture in the setting of previously untreated hypospadias.

The primary outcome was urethral patency, defined as the easy passage of a $16 \mathrm{Fr}$ flexible cystoscope at 6 and 18 months of follow-up. Patients were then followed symptomatically after scheduled cystoscopies. Secondary outcomes were the 90-day complication rates reported using the Clavien-Dindo classification and the rate of urethrocutaneous fistula.

For statistical analysis, different univariate tests were used depending on the variable characteristics. Since all numerical variables were not normally distributed the Kruskall-Wallis rank-test was used for median comparison, Fisher's exact test for proportions, while KaplanMeier, Log Rank test and Cox Proportional Hazard Model for survival multivariate analysis were utilized (Stata $12.0^{\mathrm{TM}}$ ). Two-tailed p-values $<0.05$ were considered statistically significant in all tests.

\section{Results}

Baseline patient characteristics are represented in Table 1. The median patient age was 36 years. Overall, one-third of patients had comorbidities, however only a $15.5 \%$ had a Charlson comorbidity index $\geq 1$. The presence of lichen sclerosus and erectile dysfunction was low at $5.9 \%$ and $2.4 \%$, respectively, without significant differences between various groups. The median stricture length was $5.0 \mathrm{~cm}$, with Group 1 being the longest at $6.0 \mathrm{~cm}$ and the Group 2 the shortest at $3.5 \mathrm{~cm}(\mathrm{p}=0.02)$. Patients had undergone a median of 3 previous endoscopic procedures for all groups ( $\mathrm{p}=0.24)$, with a median of 2 previous open repairs overall, being significantly higher for Group 1 at $3(\mathrm{p}<0.0001)$.

Staged reconstruction was the surgical technique most commonly used (Table 2) but 35\% of patients successfully underwent single-stage urethroplasty. Surgical techniques differed by groups, Group 1 (66.7\% of the total) required staged urethroplasty in 75\% of cases, Group 2 (7.1\% of total) typically had single stage urethroplasty with buccal mucosal graft (BMG) in $83.3 \%$ of cases while Group $3(10.7 \%)$ had a single stage reconstruction with either buccal graft 
or anastomotic urethroplasty technique in $77.8 \%$ of cases. Group 4 (15.5\% of total) required penile fasciocutaneous flap (PFF) reconstruction in 69.2\%.

Postoperative success by groups and surgical technique are demonstrated in Tables 2 and 3 respectively. Globally, urethroplasty for HAUS was successful in $88.1 \%$ of patients, with no difference between groups ( $\mathrm{p}=0.82$ ). Patients were followed-up over a median of 19.5 months, which was similar between groups $(\mathrm{p}=0.14)$. As shown in Figure 1, there were no significant differences between HAUS types in the Kaplan-Meier failure-free survival analysis (logrank test $\mathrm{p}=0.68$ ). Additionally, there were no significant preoperative nor surgical technique factors predicting for success in the Cox Proportional Hazard Model for multivariate failure-free survival analysis. Finally, when comparing success by individual surgical technique groups no significant differences were found $(\mathrm{p}=0.45)$.

Perioperative complications are also found in Tables 2 and 3. The median length of stay (LOS) was considerably higher in the Group 1 at 7 days $(\mathrm{p}<0.0001)$, given most underwent a staged procedure, requiring admission at least twice. There were 18 patients (21.4\%) presenting with early complications, however only 8 (9.5\% of the total) were categorized as Clavien-Dindo grade 2 or more. Urethrocutaneous fistula presented in $21.5 \%$ of the total, mainly at the expense of groups 1 and 4, still no relevant differences were found between groups $(p=0.19)$. Nevertheless, when comparing complication rate by technique groups, both overall early complication and Clavien-Dindo grade $>1$, along with fistula were all significantly higher for the single stage PIF group at 53.9\% ( $\mathrm{p}=0.006)$, 38.5\% $(\mathrm{p}=0.003)$ and $53.9 \%(\mathrm{p}=0.002)$, respectively. Among 4 patients undergoing anastomotic urethroplasty, 2 presented with postoperative fistula: one from Group 2 and one from Group 4. Single stage BMG urethroplasty and perineal urethrostomy showed a lower fistula rate at $0.0 \%$, and $0.0 \%$, respectively $(p=0.002)$.

Regarding other quality of life-impacting postoperative outcomes, we found that selfreported erectile dysfunction was present in $1.2 \%$ of the cases, while both chordee and scrotal/perineal pain rates were as low as $6.1 \%$ and $9.6 \%$, respectively, with no differences for either HAUS groups (Table 2) or surgical technique groups (Table 3).

\section{Discussion}

\section{Hypospadias and urethral stricture}

Urethral stricture is one the most common problems encountered in hypospadias patients presenting as adults. ${ }^{6,9,14-16}$ Although the incidence remains unclear and exact cause remains unknown, development of stricture may be related to the use of preputial flaps, tubularized tissue, or simply related to managing severe, more complex proximal hypospadias cases. ${ }^{4}$ Some argue that stricture occurs in childhood as a consequence of a poor technical repair resulting in complications that are initially undetected. ${ }^{17}$ Others speculate that hypospadias repairs deteriorate during puberty after the onset of sexual activity which may be related to the absence of the corpus spongiosum. ${ }^{10}$ There is also the possibility that stricture formation may be related 
to disproportionate growth of the urethra and surrounding spongiosum, which, over time, may result in urethral stricture. When treating HAUS, endoscopic treatments offer little chance of durable benefit given that urethral dilation and urethrotomy typically have poor success in penile strictures or strictures over $2 \mathrm{~cm}$ in length, which hypospadias strictures frequently are. ${ }^{18}$ In our study population, patients had a median stricture length of $5 \mathrm{~cm}$, a median of 3 prior endoscopic treatments and the majority of strictures (89\%) involved at least a portion of the penile urethra. Treating patients with adult hypospadias can be challenging as most patients have no record of how many repairs they had, what type of repair, the original meatal location or associated postoperative complications. Physical examination is critical to assess the size of the glans, glans cleft, ventral Dartos thickness, presence of lichen sclerosus and palpable fibrosis which all play a role in surgical decision making. ${ }^{19}$

\section{Urethroplasty success and complications}

While surgery for adult hypospadias is generally successful with reported "success" rates of 75$88 \%$ the success rate of any single surgery is approximately $50 \%$ and on average 2 or more operations are required to address the adult complications of hypospadias. ${ }^{6,9,10,12,20-}$

${ }^{23}$ Additionally, these surgeries incur a 26-68\% risk of complications and hypospadias revision surgery carries an approximate twofold risk of complications likely because the ventral penile skin and Dartos fascia are often deficient and poorly vascularized. ${ }^{6,9,10,12,20-25}$ As a consequence revision hypospadias surgery is clearly not a surgery for "dabblers" in urethral reconstruction. In this current series of surgery for hypospadias associated stricture, a stricture free success rate of $88.1 \%$ was achieved with a 90-day complication rate of $9.5 \%$ (Clavien $>1$ ) with a $21.4 \%$ rate of urethrocutaneous fistula. To accomplish this $52 \%$ required staged reconstruction but over $1 / 3$ were able to undergo single stage reconstruction. Contrary to what one would expect, postoperative erectile dysfunction, chordee and chronic pain frequency was below $10 \%$ for all cases, although a self-reported sexual function rather than of a validated questionnaire was used to assess these symptoms. ${ }^{26}$ Whether the relatively high frequency of fistula after a staged urethroplasty is due to the original hypospadias severity, the number of previous repairs or to the technique itself, cannot be adequately assessed in this study.

\section{Outcomes characterized by groups}

While this series is one of the larger series of surgery for hypospadias associated strictures, it is difficult to apply these types of findings in a clinically meaningful way without attempting to identify clinical patterns that help categorize patients and assist surgical decision making in these often-complex patients.

In order to stratify adult hypospadias complications into different risk groups, Ching and colleagues originally presented a classification system for adult hypospadias based on the status of previous surgeries. ${ }^{12}$ This classification applies to hypospadias complications in general and may not differentiate specific patients in particular those with stricture. However, dividing 
patients in the aforementioned groups, i.e. prior hypospadias repair or not, makes sense as a first step. ${ }^{6,12}$ We have further enhanced and focused this general categorization for the specific entity of hypospadias associated urethral stricture. While urethral stricture in adult patients with hypospadias can be difficult to classify meaningfully, our cohort fell into one of 4 categories based on stricture length, location, and previous surgeries. The first and most common (Group 1) was a long "pan-penile" stricture involving the majority of the penile urethra in the setting of previous (and often multiple) hypospadias surgery. These strictures tend to be longer $(6 \mathrm{~cm})$ with a median of 3 prior surgeries but highly treatable with an $89.3 \%$ stricture free rate. In these cases, the health of the spongiosum and Dartos is critical for a successful outcome of surgery. Of these patients with a robust glans, healthy corpus spongiosum and Dartos fascia were selectively (8.9\%) and successfully treated in a single stage using a substitution urethroplasty technique. When the stricture and hypospadias defect extends proximal to the coronal margin or multiple surgeries have been performed, the corpus spongiosum and Dartos are typically deficient. In these cases, a reliable and satisfactory surgical result typically requires a staged approach as seen in the majority (75\%) of our patients. ${ }^{4,27-29}$ As always, a perineal urethrostomy is a viable solution for these patients based on preference and the desire to avoid further surgeries and was used in $16.1 \%$ of patients. Shared decision making is critical in this patient population.

The second group of HAUS comprises a "junctional stricture"; a stricture of variable but relatively short length at the junction of previous hypospadias repair and native urethra. This group tends is healthier with less prior surgery (median 1.5). This type of stricture appears amenable to single-stage reconstruction using buccal mucosa with a stricture free rate of 83.3\% with minimal complications and fistulae. Although an anastomotic urethroplasty was attempted in this group, this technique failed and it is likely that this group is best managed with singlestage urethroplasty using buccal mucosa.

A third group is that of an isolated bulbar urethral stricture after previous hypospadias repair. The exact cause of these strictures may be related to the past use of perineal urethrostomy for urinary drainage following hypospadias repair, repeated instrumentation, congenital or possibly ischemic bulbar urethral stricture. These patients (90\%) were amenable to single-stage reconstruction with a high success (90\%) using a non-transecting approach and have lower rates of complications ( $0 \%$ ) and postoperative fistula formation when compared to other groups.

The last group (Group 4) is that of urethral stricture developing in the setting of previously untreated hypospadias. These can typically be managed in a single stage using contemporary single-stage hypospadias techniques such as a penile fasciocutaneous flap and decision making is based on the health of the urethral plate. $75 \%$ of patients in this group underwent single-stage urethroplasty using a penile fasciocutaneous flap, however, the 90-day complication rate was as high as $54 \%$ and $39 \%$ were classified as Clavien Grade $>1$. This fact demystifies the belief that skin must be used whenever it is available, reaffirming the trend toward the use of buccal grafts as the first line surgical technique when the urethral plate, glans cleft and Dartos fascia permits. 
While technical details are critical, regardless of significant differences in stricture length, localization and number of previous repairs, the proposed HAUS classification groups did not significantly differ in terms of urethroplasty success $(p=0.82)$, Clavien-Dindo complications $(\mathrm{p}=0.16)$ or urethrocutaneous fistula $(\mathrm{p}=0.18)$. A treatment algorithm (Figure 2$)$ may help to achieve a clearer picture of the complex HAUS scenario and serve to better categorize future studies.

Based on our data, anastomotic urethroplasty might seem to be discouraged for HAUS, however, newer non-transecting techniques are a viable option for hypospadias strictures especially those in group 3. Complications predominantly arose when this technique was attempted in other groups.

\section{Study limitations}

To our knowledge, this is one of the largest series of HAUS patients and adequately represents the broad clinical spectrum and complexity of HAUS presentation in adults. In spite of this, the sample size is still relatively small and we believe that multi-institutional database analysis will require to obtain more statistical power, answer key questions and provide generalizable results. Another deficiency of our study is its retrospective design and as a consequence, we did not find reliable data regarding the original hypospadias presentation. Also, while our classification scheme fits certain patterns of patients found at our center, not all patients will be captured in this system. Although the vast majority of the patients within each group were treated with unique patterns of surgical techniques there was variability in management within each group.

\section{Conclusion}

Urethroplasty for HAUS is highly successful but patients frequently require more than one operation and have a significant risk of complications and urethrocutaneous fistula. In particular, use of penile fasciocutaneous flaps has higher rates of associated complications. While over half of patients require staged reconstruction, over $1 / 3$ are able to selectively undergo successful single stage urethroplasty. Despite a broad spectrum of presentation and complexity patients can often be categorized in one of four groups based on stricture length, location and number of previous procedures. A classification-based approach can help direct decision making and obtain similar outcomes regardless of baseline differences. 


\section{References}

1. Paulozzi LJ, Erickson JD, Jackson RJ. Hypospadias trends in two US surveillance systems. Pediatrics. 1997;100(5):831-834.

2. Cimador M, Vallasciani S, Manzoni G, Rigamonti W, De Grazia E, Castagnetti M. Failed hypospadias in paediatric patients. Nat Rev Urol. 2013;10(11):657-666. doi:10.1038/nrurol.2013.164

3. Lee OT, Durbin-Johnson B, Kurzrock EA. Predictors of secondary surgery after hypospadias repair: A population based analysis of 5,000 patients. J Urol. 2013;190(1):251-255. doi:10.1016/j.juro.2013.01.091

4. Snodgrass WT, Bush NC. Management of Urethral Strictures After Hypospadias Repair. Urol Clin North Am. 2017 Feb;44(1):105-111.

5. Nuininga JE, De Gier RPE, Verschuren R, et al. Long-term outcome of different types of 1-stage hypospadias repair. J Urol. Vol 174. ; 2005:1544-1548. doi:10.1097/01.ju.0000179255.55848.50

6. Hoy NY, Rourke KF. Better Defining the Spectrum of Adult Hypospadias: Examining the Effect of Childhood Surgery on Adult Presentation. Urology. 2017;99:281-286. doi:10.1016/j.urology.2016.07.057

7. Lumen N, Hoebeke P, Willemsen P, De Troyer B, Pieters R, Oosterlinck W. Etiology of urethral stricture disease in the 21st century. J Urol. 2009 Sep;182(3):983-987.

8. Palminteri E, Berdondini E, Verze P, De Nunzio C, Vitarelli A, Carmignani L. Contemporary urethral stricture characteristics in the developed world. Urology. 2013;81(1):191-196. doi:10.1016/j.urology.2012.08.062

9. Myers JB, McAninch JW, Erickson BA, Breyer BN. Treatment of adults with complications from previous hypospadias surgery. J Urol. 2012;188(2):459-463. doi:10.1016/j.juro.2012.04.007

10. Barbagli G, De Angelis M, Palminteri E, Lazzeri M. Failed Hypospadias Repair Presenting in Adults. Eur Urol. 2006;49(5):887-895. doi:10.1016/j.eururo.2006.01.027

11. Mundy AR. Failed hypospadias repair presenting in adults. Eur Urol. 2006 May;49(5):774-776.

12. Ching CB, Wood HM, Ross JH, Gao T, Angermeier KW. The Cleveland Clinic experience with adult hypospadias patients undergoing repair: Their presentation and a new classification system. BJU Int. 2011;107(7):1142-1146. doi:10.1111/j.1464410X.2010.09693.

13. Dindo D, Demartines N, Clavien PA. Classification of surgical complications: A new proposal with evaluation in a cohort of 6336 patients and results of a survey. Ann Surg. 2004;240(2):205-213. doi:10.1097/01.sla.0000133083.54934.

14. Duel BP, Barthold JS, Gonzalez R. Management of urethral strictures after hypospadias repair. J Urol 1998;160;170-171.

15. Tang SH, Hammer CC, Doumanian L, et al. Adult urethral stricture disease after childhood hypospadias repair. Adv Urol. 2008 Nov [cited 2016 Feb 18].

16. Kozinn SI, Harty NJ, Zinman L, Buckley JC. Management of complex anterior urethral strictures with multistage buccal mucosa graft reconstruction. Urology. 2013 Sep;82(3):718-722. 
17. Bush BC. Re: Better Defining the Spectrum of Adult Hypospadias: Examining the Effect of Childhood Surgery on Adult Presentation Urology. 2017 Jan;99: 286-287.

18. Pansadoro V, Emiliozzi P. Internal urethrotomy in the management of anterior urethral strictures: long-term followup. J Urol. 1996 Jul;156(1):73-75.

19. Rourke K, Braga LH. Transitioning patients with hypospadias and other penile abnormalities to adulthood: What to expect? Can Urol Assoc J. 2018 Apr;12(4 Suppl 1):S27-S33. doi: 10.5489/cuaj.5227.

20. Hensle TW, Tennenbaum SY, Reiley EA, Pollard J. Hypospadias repair in adults: adventures and misadventures. J Urol. 2001 Jan;165(1):77-79.

21. Craig JR, Wallis C, Brant WO, et al. Management of adults with prior failed hypospadias surgery. Transl Androl Urol. 2014;3:196-204.

22. Barbagli G, Perovic S, Djinovic R, Sansalone S, Lazzeri M. Retrospective descriptive analysis of 1,176 patients with failed hypospadias repair. J Urol. 2010 Jan;183(1):207211.

23. Secrest CL, Jordan GH, Winslow BH, Horton CE, McCraw JB, Gilbert DA, Devine CJ Jr. Repair of the complications of hypospadias surgery. J Urol. 1993 Nov;150(5 Pt 1):1415-1418.

24. Snodgrass W, Villanueva C, Bush N. Primary and reoperative hypospadias repair in adults - are results different than in children? J Urol. 2014;192:1730-1733.

25. Baskin LS, Ebbers MB. Hypospadias: Anatomy, etiology, and technique. J Pediatr Surg. 2006;41(3):463-472. doi:10.1016/j.jpedsurg.2005.11.059

26. Mieusset R, Soulie M. Hypospadias: psychosocial, sexual, and reproductive consequences in adult life. J Androl 2005;26: 163-168.

27. Kozinn SI, Harty NJ, Zinman L, et al. Management of complex anterior urethral strictures with multistage buccal mucosa graft reconstruction. Urology 2013; 82:718722.

28. Meeks JJ, Erickson BA, Gonzalez CM. Staged reconstruction of long segment urethral strictures in men with previous pediatric hypospadias repair. J Urol. 2009 Feb;181(2):685-689.

29. Morrison CD, Cinà DP, Gonzalez CM, Hofer MD. Surgical Approaches and Long-Term Outcomes in Adults with Complex Reoperative Hypospadias Repair. J Urol. 2018 May;199(5):1296-1301. doi: 10.1016/j.juro.2017.11.078. 


\section{Figures and Tables}

Fig. 1. Failure-free survival analysis stratified by hypospadias-associated urethral stricture groups.

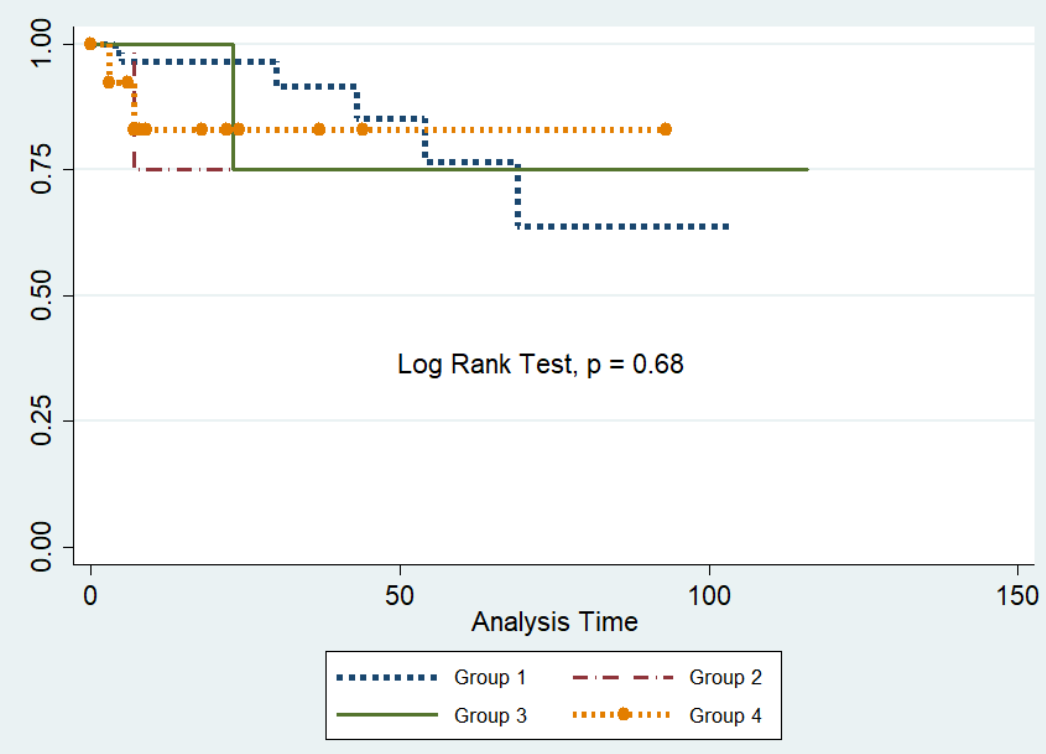


Fig. 2. Proposed algorithm for hypospadias-associated urethral stricture (HAUS) management. BMG: buccal mucosal graft.

\section{Failed Previous} Repair with Long Penile Stricture

1. Staged BMG Urethroplasty

2. Perineal Urethrostomy

\section{HAUS}

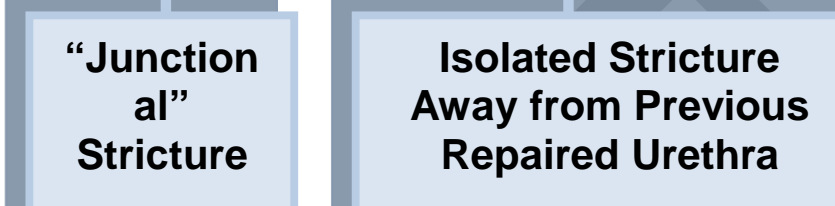

\section{Yes}

\section{Chordee?}
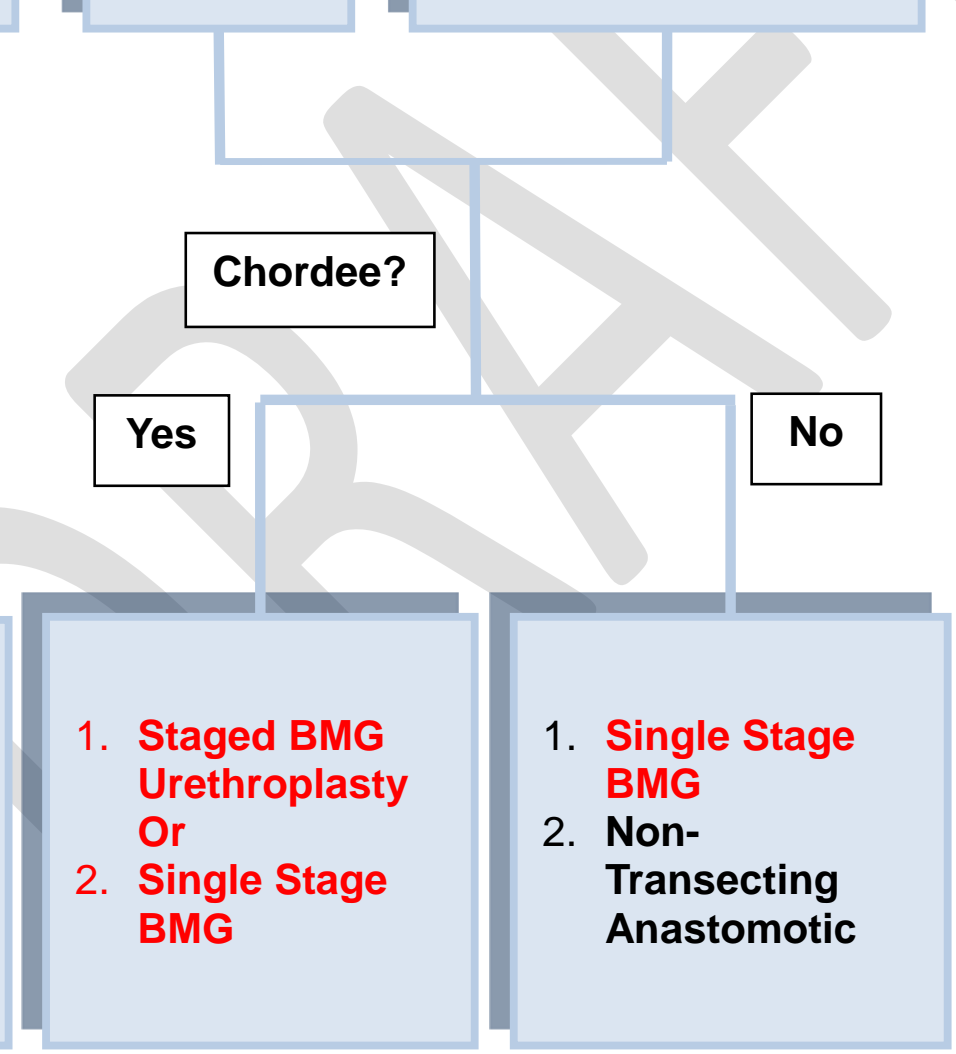

1. Staged BMG Urethroplasty Or

2. Single Stage BMG

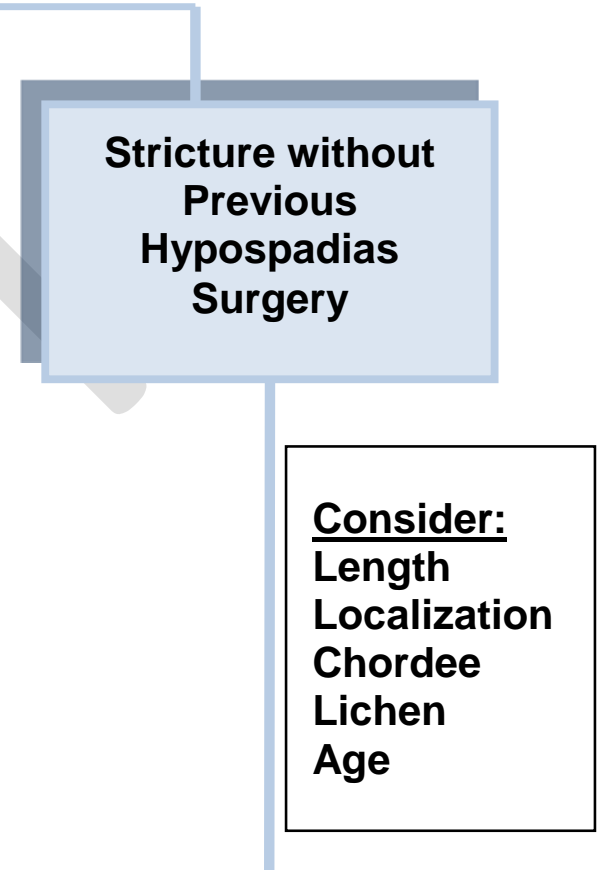

1. Single Stage BMG

2. NonTransecting Anastomotic

3. Staged BMG

4. Perineal Urethrostomy 


\begin{tabular}{|c|c|c|c|c|c|c|}
\hline Characteristics & Overall & $\begin{array}{c}\text { Group 1: } \\
\text { Previous } \\
\text { repair and } \\
\text { long penile } \\
\text { stricture }\end{array}$ & $\begin{array}{c}\text { Group 2: } \\
\text { Junctional } \\
\text { stricture }\end{array}$ & $\begin{array}{c}\text { Group 3: } \\
\text { Isolated } \\
\text { bulbar } \\
\text { stricture }\end{array}$ & $\begin{array}{c}\text { Group 4: } \\
\text { Stricture in } \\
\text { non- } \\
\text { repaired } \\
\text { hypospadias }\end{array}$ & $\mathbf{p}$ \\
\hline Number of patients (\%) & $84(100)$ & $56(66.7)$ & $6(7.1)$ & $9(10.7)$ & $13(15.5)$ & $\mathrm{n} / \mathrm{a}$ \\
\hline Median age, years (SD) & $36(14.2)$ & $36(14.5)$ & $35.5(13.9)$ & $40(15.5)$ & 33 (13.9) & $0.90^{*}$ \\
\hline Comorbidities, n (\%) & $25(29.8)$ & 19 (33.9) & 0 & $2(22.2)$ & $4(30.8)$ & $0.41^{* *}$ \\
\hline Charlson scale $\geq 1$, n (\%) & $13(15.5)$ & $10(17.9)$ & 0 & 0 & $3(23.1)$ & $0.47^{* *}$ \\
\hline Lichen sclerosus present, n (\%) & $5(5.9)$ & $4(7.1)$ & 0 & $1(11.1)$ & 0 & $0.72^{* *}$ \\
\hline $\begin{array}{l}\text { Preoperative erectile } \\
\text { dysfunction, n (\%) }\end{array}$ & $2(2.4)$ & $1(1.8)$ & 0 & $1(11.1)$ & 0 & $0.35^{* *}$ \\
\hline Median stricture length, cm (SD) & $5.0(2.9)$ & $6.0(2.6)$ & $3.5(1.5)$ & $5.0(3.6)$ & $4.0(3.7)$ & $0.02^{*}$ \\
\hline $\begin{array}{l}\text { Median number of previous } \\
\text { repairs, } n(S D)\end{array}$ & $2.0(2.1)$ & $3.0(2.0)$ & $1.5(2.1)$ & $2.0(1.4)$ & $0.0(0.0)$ & $0.0001^{*}$ \\
\hline $\begin{array}{l}\text { Median number of previous } \\
\text { endoscopic procedures, } n \text { (SD) }\end{array}$ & $3.0(8.9)$ & $3.0(3.4)$ & $1.5(1.2)$ & $3.0(2.9)$ & $1(21.8)$ & $0.24^{*}$ \\
\hline
\end{tabular}

* Kruskall-Wallis test for median differences; ${ }^{* *}$ Fisher's exact test. Comorbidities includes diabetes, chronic obstructive pulmonary disease, smoking, and body mass index $>35$. SD: standard deviation. 
Table 2. Postoperative outcomes by HAUS groups

\begin{tabular}{|c|c|c|c|c|c|c|}
\hline Outcomes & Overall & $\begin{array}{l}\text { Group 1: } \\
\text { Previous } \\
\text { repair } \\
\text { and long } \\
\text { penile } \\
\text { stricture } \\
\end{array}$ & $\begin{array}{c}\text { Group 2: } \\
\text { Junctional } \\
\text { stricture }\end{array}$ & $\begin{array}{l}\text { Group 3: } \\
\text { Isolated } \\
\text { bulbar } \\
\text { stricture }\end{array}$ & $\begin{array}{c}\text { Group 4: } \\
\text { Stricture in } \\
\text { non- } \\
\text { repaired } \\
\text { hypospadias }\end{array}$ & $\mathbf{p}$ \\
\hline $\begin{array}{l}\text { Number of patients, n (\%) } \\
\text { Staged } \\
\text { Single-stage BMG } \\
\text { Single-stage penile flap } \\
\text { Anastomotic } \\
\text { Perineal urethrostomy }\end{array}$ & $\begin{array}{c}84(100) \\
44(52.4) \\
13(15.5) \\
13(15.5) \\
4(4.8) \\
10(11.9)\end{array}$ & $\begin{array}{c}56(66.7) \\
42(75.0) \\
1(1.8) \\
4(7.1) \\
0 \\
9(16.1)\end{array}$ & $\begin{array}{c}6(7.1) \\
0 \\
5(83.3) \\
0 \\
1(16.7) \\
0\end{array}$ & $\begin{array}{l}9(10.7) \\
1(11.1) \\
6(66.7) \\
0 \\
1(11.1) \\
1(11.1)\end{array}$ & $\begin{array}{c}13(15.5) \\
1(7.7) \\
1(7.7) \\
9(69.2) \\
2(15.4) \\
0\end{array}$ & $0.000^{*}$ \\
\hline Any 90-day complication, n (\%) & $18(21.4)$ & $11(19.6)$ & $2(33.3)$ & 0 & $5(38.5)$ & $0.11^{*}$ \\
\hline Clavien grade $\geq 2, \mathrm{n}(\%)$ & $8(9.5)$ & $4(7.1)$ & $1(16.7)$ & 0 & $3(23.1)$ & $0.16^{*}$ \\
\hline Chordee, n (\%) & $5(6.1)$ & $3(5.4)$ & 0 & $1(12.5)$ & $1(7.7)$ & $0.58^{*}$ \\
\hline Erectile dysfunction, n (\%) & $1(1.2)$ & $1(1.8)$ & 0 & 0 & 0 & $1.00^{*}$ \\
\hline Scrotal/perineal pain, n (\%) & $8(9.5)$ & $6(10.7)$ & 1 (16.7) & 0 & $1(7.7)$ & $0.64^{*}$ \\
\hline Postoperative fistula, n (\%) & $18(21.4)$ & $12(21.4)$ & $1(16.7)$ & 0 & $5(38.5)$ & $0.19^{*}$ \\
\hline $\begin{array}{l}\text { Median postoperative lenght of } \\
\text { stay (days) (SD) }\end{array}$ & $6(2.4)$ & $7(2.1)$ & $2(0.0)$ & $3(1.5)$ & $2(1.4)$ & $0.000^{* *}$ \\
\hline Stricture recurrence, $\mathrm{n}(\%)$ & $10(11.9)$ & $6(10.7)$ & 1 (16.7) & 1 (11.1) & 1 (15.4) & $0.82^{*}$ \\
\hline $\begin{array}{l}\text { Median followup time, months } \\
\text { (SD) }\end{array}$ & $\begin{array}{c}19.5 \\
(26.34) \\
\end{array}$ & $21.0(25.6)$ & $8.5(11.1)$ & $\begin{array}{c}13.0 \\
(38.0) \\
\end{array}$ & $9.0(24.9)$ & $0.13^{* *}$ \\
\hline
\end{tabular}

*Fisher's exact test; ${ }^{* *}$ Kruskall-Wallis test for median differences. BMG: buccal mucosal graft; HAUS: hypospadias-associated urethral strictures; SD: standard deviation. 


\section{Table 3. Postoperative outcomes by surgical technique used}

\begin{tabular}{|c|c|c|c|c|c|c|c|}
\hline Outcomes & Overall & Staged & $\begin{array}{c}\text { Single } \\
\text { stage } \\
\text { BMG } \\
\end{array}$ & $\begin{array}{c}\text { Single } \\
\text { stage } \\
\text { PIF }\end{array}$ & Anastomotic & Urethrostomy & $\mathbf{p}$ \\
\hline Number of patients, n (\%) & $84(100)$ & $\begin{array}{c}44 \\
(52.4)\end{array}$ & $13(15.4)$ & $\begin{array}{c}13 \\
(15.4)\end{array}$ & $4(4.8)$ & $10(11.9)$ & $\mathrm{n} / \mathrm{a}$ \\
\hline $\begin{array}{l}\text { Any 90-day complication, } \\
\mathrm{n}(\%)\end{array}$ & $18(21.4)$ & $8(18.2)$ & $1(7.7)$ & $7(53.9)$ & $2(50.0)$ & 0 & $0.006^{*}$ \\
\hline Clavien grade $\geq 2, \mathrm{n}(\%)$ & $8(9.5)$ & $1(2.3)$ & $1(7.7)$ & $5(38.5)$ & $1(25.0)$ & 0 & $0.003^{*}$ \\
\hline Chordee, n (\%) & $5(6.1)$ & $4(9.1)$ & $1(7.7)$ & 0 & 0 & 0 & $0.797^{*}$ \\
\hline $\begin{array}{l}\text { Erectile dysfunction, } n \\
\text { (\%) }\end{array}$ & $1(1.2)$ & 0 & 0 & $1(7.7)$ & 0 & 0 & $0.470^{*}$ \\
\hline $\begin{array}{l}\text { Scrotal/perineal pain, } n \\
\text { (\%) }\end{array}$ & $8(9.5)$ & $4(9.1)$ & $1(7.7)$ & $1(7.7)$ & $1(25.0)$ & $1(10.0)$ & $0.771^{*}$ \\
\hline $\begin{array}{l}\text { Postoperative fistula, } n \\
\text { (\%) }\end{array}$ & $18(21.4)$ & $9(20.5)$ & 0 & 7 (53.9) & $2(50.0)$ & 0.0 & $0.002^{*}$ \\
\hline $\begin{array}{l}\text { Median postoperative } \\
\text { length of stay, days (SD) }\end{array}$ & $6(2.4)$ & $7(0.6)$ & $2(0.5)$ & $2(0.5)$ & $2(0.0)$ & $2.5(1.9)$ & $0.0001^{* * 2}$ \\
\hline Stricture recurrence, $\mathrm{n}(\%)$ & $10(11.9)$ & $4(9.1)$ & $1(7.7)$ & $3(23.1)$ & $1(25.0)$ & $1(10.0)$ & $0.446^{*}$ \\
\hline
\end{tabular}

${ }^{*}$ Fisher's exact test; ${ }^{* *}$ Kruskall-Wallis test for median differences. BMG: buccal mucosal graft; SD: standard deviation. 